\title{
Effect of supplementation of green tea polyphenols on the developmental competence of bovine oocytes in vitro
}

Z.G. Wang, S.D. Yu and
Key Laboratory for Molecular Animal Nutrition, Ministry of Education,

College of Animal Science, Zhejiang University, Hang Zhou, Zhejiang, China
Correspondence

S.D. Yu

College of Animal Science

Zhejiang University

Huajiachi Campus

Hang Zhou 310029

China

Fax: +86-571-86994963

E-mail: wzhguang68@yahoo.com

Research supported by the Zhejiang Science and Technology Committee (grant No. 2004C12037).

....................

Received May 25, 2006 Accepted March 26, 2007

\begin{abstract}
The objective of the present study was to examine the effect of green tea polyphenols (GTPs) supplementation during in vitro maturation, in vitro fertilization, and in vitro culture on the developmental competence of bovine oocytes. Cumulus-oocyte complexes aspirated from the ovaries were matured in vitro $\left(38.5^{\circ} \mathrm{C}\right.$ for $\left.24 \mathrm{~h}\right)$ and fertilized $\left(38.5^{\circ} \mathrm{C}\right.$ for $\left.15-18 \mathrm{~h}\right)$ and embryos were cultured $\left(38.5^{\circ} \mathrm{C}\right.$ for $\left.192 \mathrm{~h}\right)$ in a defined conditioned medium with or without GTPs supplementation. The GTPs used in the present study contained $99 \%$ catechin derivatives, with the major components being $50 \%$ (-)-epigallocatechin gallate, $22 \%$ (-)-epicatechin gallate, $18 \%$ (-)-epigallocatechin, and $10 \%(-)$-epicatechin. Four replicate trials were done for each type of experiment. GTPs supplementation $(15 \mu \mathrm{M})$ of the maturation medium led to a significant increase in the rate of blastocyst formation (34.0 vs $21.4 \%, \mathrm{P}<0.05$ ). However, the rate of blastocyst formation was not improved when higher GTPs concentrations (20 or $25 \mu \mathrm{M})$ were added to the in vitro maturation medium. During in vitro fertilization, supplementation with higher GTPs concentrations (20 or $25 \mu \mathrm{M})$ significantly reduced the rate of blastocyst formation $(\mathrm{P}<$ 0.05). Supplementation of the culture medium with $15 \mu \mathrm{M}$ GTPs improved the rate of blastocyst formation, while higher GTPs concentrations $(25 \mu \mathrm{M})$ significantly reduced embryo development $(\mathrm{P}<$ $0.05)$. In conclusion, these results demonstrate that supplementation with GTPs at low concentration $(15 \mu \mathrm{M})$ during in vitro maturation and in vitro culture improved the developmental competence of bovine oocytes.
\end{abstract}

\section{Introduction}

The formation of reactive oxygen species (ROS) such as superoxide anions $\left(\mathrm{O}_{2}^{-}\right)$, hydroxyl radicals $(\mathrm{OH} \cdot)$ and hydrogen peroxide $\left(\mathrm{H}_{2} \mathrm{O}_{2}\right)$ is a normal process that occurs in the cell when there is a deviation of electrons to oxygen $\left(\mathrm{O}_{2}\right)$ during electron transfer reactions (1). There is some evidence that ROS may be
Key words

- Bovine oocytes

- In vitro culture

- Green tea polyphenols

- Embryo development 
In vitro oocyte or embryo culture results in higher $\mathrm{O}_{2}$ concentrations than in in vivo environments, leading to increased ROS levels (7). ROS such as $\mathrm{O}_{2}^{-\cdot}$ are able to diffuse and pass through cell membranes and alter most types of cellular molecules such as lipids, proteins and nucleic acids. This can affect the early development of mouse, hamster, and bovine embryos (8-10). Living organisms possess natural protective equivalents known as ROS scavengers (antioxidants) that counteract the negative effects of ROS. These antioxidants include enzymes such as superoxide dismutase, which will eliminate $\mathrm{O}_{2}^{-\cdot}$, catalase and selenium-dependent glutathione peroxidase, which will transform $\mathrm{H}_{2} \mathrm{O}_{2}$ into $\mathrm{H}_{2} \mathrm{O}$ and $\mathrm{O}_{2}$, as well as lipidand water-soluble antioxidants such as vitamins C, E and uric acid (11). However, during in vitro oocyte and embryo culture the levels of antioxidants are lower than in vivo because the oocytes or embryos are divorced from the donor body and do not benefit from the maternal antioxidant protection. The addition of an antioxidant to the medium, therefore, may be important for in vitro oocyte maturation and in vitro embryo culture.

Tea (Camellia sinensis) is one of the most popular beverages consumed worldwide. Green tea polyphenols (GTPs) are the major water-soluble components of green tea infusions. The major GTPs are (-)-epigallocatechin gallate (EGCG), (-)-epicatechin gallate (ECG), (-)-epicatechin (EC), and (-)-epigallocatechin (EGC). These catechins have a strong antioxidant activity (12) and are potent scavengers of ROS superoxide, hydrogen peroxide, hydroxyl radicals, and nitric oxide produced by various chemicals (13).

There are no reports on the use of GTPs during in vitro maturation (IVM) of bovine oocytes and in vitro culture (IVC) of bovine embryos. Thus, the objective of the present study was to examine the effects of GTPs supplementation during IVM, in vitro fertili- zation (IVF) and IVC on the developmental competence of bovine oocytes.

\section{Material and Methods}

\section{Reagents}

All chemicals and media were purchased from Sigma (St. Louis, MO, USA) unless otherwise indicated. The green tea polyphenols (from the Tea Department of Zhejiang University) used in the present study contained $99 \%$ catechin derivatives, with the major components being 50\% EGCG, 22\% ECG, $18 \%$ EGC, and $10 \%$ EC. The average molecular weight of GTPs was estimated on the basis of the percent presence of major components.

\section{In vitro maturation}

Cumulus-oocyte complexes (COCs) were aspirated from 2- to 6-mm follicles of bovine ovaries obtained from a slaughterhouse. Oocytes with intact cumulus cells and evenly granulated cytoplasm were selected and randomly assigned to each treatment. Ten COCs were washed and incubated with droplets of IVM medium, which consisted of modified synthetic oviduct fluid (m-SOF) supplemented with minimum essential medium non-essential amino acids (Gibco, Grand Island, NY, USA), minimum essential medium essential amino acids (Gibco), $1.5 \mathrm{mM}$ glucose, and 1 $\mathrm{mM}$ glutamine. The SOF medium used in this study was based on the original formulation (14), with subsequent modifications (15). The IVM drops were covered with mineral oil and incubated at $38.5^{\circ} \mathrm{C}$ in $5 \% \mathrm{CO}_{2}$ in air at saturated humidity for $24 \mathrm{~h}$.

\section{In vitro fertilization}

The matured COCs were washed twice in warm HEPES-buffered Tyrode albumin lactate pyruvate solution (HEPES-TALP) (16) and once in IVF medium (a bicarbonate- 
buffered modified TALP) (17) and then placed in $50-\mu \mathrm{L}$ droplets (10-12 COCs per droplet) of IVF medium containing $10 \mu \mathrm{g} /$ $\mathrm{mL}$ heparin. Frozen bull semen was thawed and prepared by the swim-up procedure (17). Sperm cells were added to the IVF drops at a final concentration of $2 \times 10^{6} / \mathrm{mL}$. Incubation was carried out at $38.5^{\circ} \mathrm{C}$ in $5 \% \mathrm{CO}_{2}$ in air at saturated humidity for $15-18 \mathrm{~h}$.

\section{In vitro culture}

Between 15 and $18 \mathrm{~h}$ after insemination, surrounding cumulus cells of presumptive zygotes were denuded by repeated pipetting in phosphate-buffered saline (PBS) and subsequently washed three times in PBS before being transferred to the IVC drops (20-30 embryos/50- $\mu \mathrm{L}$ drops). In all experiments, embryos were cultured in m-SOF medium containing $0.8 \%$ bovine serum albumin at $38.5^{\circ} \mathrm{C}$ in $5 \% \mathrm{CO}_{2}$ and $7 \% \mathrm{O}_{2}$ with high humidity.

Cleavage and development of embryos to the blastocyst stage were assessed at 48 and $192 \mathrm{~h}$ (i.e., on 8th day) post-insemination, respectively, under a stereomicroscope (60X). After removing the zona pellucida by immersing in acid Tyrode solution, $\mathrm{pH} 2.5$, blastocysts were fixed in ethanol:acetic acid (3:1) and stained with $0.24 \%$ basic fuchsin. The number of cells in blastocysts was examined by phase contrast microscopy.

\section{Experimental design}

Three separate experiments were performed to evaluate the effects of supplementation with GTPs at different concentrations during different phases of the in vitro production of bovine embryos. In Experiment 1 , the GTPs at different concentrations ( 0 , $10,15,20$, or $25 \mu \mathrm{M}$ ) were added during IVM in defined condition medium under $20 \% \mathrm{O}_{2}$ to reduce ROS production in the IVM medium. Oocytes cultured without GTPs supplementation were used as control.
In Experiment 2, bovine oocytes were matured in GTPs-free maturation medium. Oocytes were inseminated in the fertilization medium with different concentration of GTPs $(0,10,15,20$, or $25 \mu \mathrm{M})$ under high (20\%) $\mathrm{O}_{2}$ concentration and then compared with the control group (GTPs-free fertilization medium).

In Experiment 3, oocytes were matured and inseminated in GTPs-free medium. Various concentrations of GTPs $(0,10,15,20$, or $25 \mu \mathrm{M})$ were added to the culture medium under low $\mathrm{O}_{2}(7 \%)$.

\section{Statistical analysis}

Data from four replicate trials were analyzed statistically for comparison of each treatment by ANOVA and the Fisher protected least significant difference test using the STATVIEW program (Abacus Concepts, Inc., Berkeley, CA, USA). All percent values were subjected to arc sine transformation before statistical analysis. Data are reported as means \pm SEM. A probability of $\mathrm{P}<0.05$ was considered to be statistically significant.

\section{Results}

In the first experiment (Table 1), oocytes were cultured for $24 \mathrm{~h}$ in IVM medium

Table 1. Effect of green tea polyphenols (GTPs) concentration in the maturation medium on the development of bovine embryos in vitro.

\begin{tabular}{lcccc}
\hline \multirow{2}{*}{$\begin{array}{l}\text { GTPs } \\
\text { concentration } \\
(\mu \mathrm{M})\end{array}$} & $\begin{array}{c}\text { No. of } \\
\text { oocytes } \\
\text { inseminated }\end{array}$ & Cleavage $(\%)^{\mathrm{a}}$ & Blastocyst $(\%)^{\mathrm{b}}$ & \multirow{2}{*}{$\begin{array}{c}\text { Number of cells } \\
\text { in blastocysts }\end{array}$} \\
\cline { 3 - 4 } & 109 & $79(72.3 \pm 1.3)$ & $17(21.4 \pm 2.9)^{\mathrm{d}, \mathrm{e}}$ & $105 \pm 7.2^{\mathrm{c}}$ \\
0 & 121 & $91(75.2 \pm 1.1)$ & $27(29.5 \pm 1.2)^{\mathrm{c}, \mathrm{d}}$ & $123 \pm 3.1^{\mathrm{d}, \mathrm{e}}$ \\
10 & 115 & $85(73.9 \pm 2.7)$ & $29(34.0 \pm 2.3)^{\mathrm{c}}$ & $117 \pm 4.9^{\mathrm{d}}$ \\
15 & 110 & $86(78.3 \pm 3.3)$ & $22(25.3 \pm 3.1)^{\mathrm{d}}$ & $129 \pm 5.2^{\mathrm{e}}$ \\
20 & 107 & $78(72.7 \pm 0.9)$ & $12(15.2 \pm 1.7)^{\mathrm{e}}$ & $120 \pm 4.3^{\mathrm{d}, \mathrm{e}}$
\end{tabular}

aNumber of embryos is reported as median and percent of embryos cleaved as percent of the number of inseminated oocytes (mean \pm SEM), or bpercent of blastocysts as percent of the number of cleaved embryos (mean $\pm \mathrm{SEM}$ ). ${ }^{\mathrm{c}, \mathrm{d}, \mathrm{e}}$ Values with different superscripts within a column are significantly different from each other $(\mathrm{P}<$ 0.05 , ANOVA followed by the Fisher protected least significant difference test). 
supplemented with GTPs at various concentrations and then fertilized in vitro and transferred to IVC medium to assess the cleavage rates. There were no significant differences in cleavage rate among treatments. However, on the 8th day after transfer in $7 \% \mathrm{O}_{2}$, the presence of $15 \mu \mathrm{M}$ GTPs during IVM significantly increased $(\mathrm{P}<0.05)$ the rate of blastocyst formation and the cell number of blastocysts compared to control (34.0 vs $21.4 \%$ and 117 vs 105\%). The cell numbers of blastocysts were significantly higher in all four treatment groups than in the control group $(\mathrm{P}<0.05)$. However, treatment with GTPs at a concentration of $25 \mu \mathrm{M}$ showed a

Table 2. Effect of green tea polyphenols (GTPs) concentration in the fertilization medium on the development of bovine embryos in vitro.

\begin{tabular}{|c|c|c|c|c|}
\hline \multirow{2}{*}{$\begin{array}{l}\text { GTPs } \\
\text { concentration } \\
(\mu \mathrm{M})\end{array}$} & \multirow{2}{*}{$\begin{array}{c}\text { No. of } \\
\text { oocytes } \\
\text { inseminated }\end{array}$} & \multicolumn{2}{|c|}{ No. of embryos } & \multirow{2}{*}{$\begin{array}{l}\text { Number of cells } \\
\text { in blastocysts }\end{array}$} \\
\hline & & Cleavage $(\%)^{a}$ & Blastocyst $(\%)^{b}$ & \\
\hline 0 & 106 & $84(79.3 \pm 2.4)^{c}$ & $21(25.1 \pm 1.8)^{c}$ & $98 \pm 5.2^{c}$ \\
\hline 10 & 110 & $86(78.3 \pm 3.1)^{c}$ & $20(23.2 \pm 1.3)^{\mathrm{cd}}$ & $113 \pm 2.1^{d}$ \\
\hline 15 & 117 & $74(63.5 \pm 2.5)^{d}$ & $14(19.0 \pm 2.0)^{d}$ & $117 \pm 1.9^{d}$ \\
\hline 20 & 121 & $76(62.7 \pm 3.3)^{d}$ & $12(15.8 \pm 2.1)^{\mathrm{de}}$ & $106 \pm 3.2^{c}$ \\
\hline 25 & 108 & $65(60.4 \pm 2.7)^{d}$ & $5(7.7 \pm 1.9)^{f}$ & $103 \pm 2.7^{c}$ \\
\hline
\end{tabular}

aNumber of embryos is reported as median and percent of embryos cleaved as percent of the number of inseminated oocytes (mean \pm SEM), or bpercent of blastocysts as percent of the number of cleaved embryos (mean \pm SEM). ${ }^{c, d, e V a l u e s ~ w i t h ~}$ different superscripts within a column are significantly different from each other ( $P<$ 0.05 , ANOVA followed by the Fisher protected least significant difference test).

Table 3. Effect of green tea polyphenols (GTPs) concentration in the culture medium on the development of bovine embryos in vitro.

\begin{tabular}{lcccc}
\hline \multirow{2}{*}{$\begin{array}{l}\text { GTPs } \\
\text { concentration } \\
(\mu \mathrm{M})\end{array}$} & $\begin{array}{c}\text { No. of } \\
\text { oocytes } \\
\text { inseminated }\end{array}$ & Cleavage $(\%)^{\mathrm{a}}$ & Blastocyst $(\%)^{\mathrm{b}}$ & \multirow{2}{*}{$\begin{array}{c}\text { Number of cells } \\
\text { in blastocysts }\end{array}$} \\
\cline { 3 - 4 } & 99 & $76(76.7 \pm 2.3)$ & $16(21.3 \pm 1.1)^{\mathrm{d}}$ & $109 \pm 3.9^{\mathrm{c}}$ \\
0 & 111 & $88(79.3 \pm 1.9)$ & $20(22.8 \pm 1.3)^{\mathrm{d}}$ & $103 \pm 2.2^{\mathrm{c}}$ \\
10 & 105 & $84(80.1 \pm 2.0)$ & $26(30.6 \pm 1.8)^{\mathrm{c}}$ & $113 \pm 3.1^{\mathrm{d}, \mathrm{e}}$ \\
15 & 110 & $86(78.2 \pm 2.7)$ & $17(19.7 \pm 2.1)^{\mathrm{d}}$ & $120 \pm 3.2^{\mathrm{d}}$ \\
20 & 109 & $87(79.8 \pm 2.1)$ & $11(12.7 \pm 0.9)^{\mathrm{e}}$ & $105 \pm 4.7^{\mathrm{c}}$ \\
25 & & & &
\end{tabular}

aNumber of embryos is reported as median and percent of embryos cleaved as percent of the number of inseminated oocytes (mean \pm SEM), or bpercent of blastocysts as percent of the number of cleaved embryos (mean \pm SEM). c,d,eValues with different superscripts within a column are significantly different from each other $(P<$ 0.05 , ANOVA followed by the Fisher protected least significant difference test). significantly reduced number of blastocysts $(\mathrm{P}<0.05)$.

In the second experiment (Table 2), oocytes were matured in GTPs-free maturation medium and fertilized in IVF medium supplemented with GTPs at various concentrations $(0,10,15,20$, or $25 \mu \mathrm{M})$. No improvement in cleavage or blastocyst rate was found when $10 \mu \mathrm{M}$ GTPs was added to the fertilization medium compared to control (78.3 vs $79.3 \%$ and 23.2 vs $25.1 \%$ ). However, supplementation with GTPs at 15,20 , and 25 $\mu \mathrm{M}$ concentrations significantly decreased the cleavage rates compared to control $(\mathrm{P}<$ 0.05). Furthermore, higher concentrations of GTPs (20 and $25 \mu \mathrm{M})$ significantly reduced $(\mathrm{P}<0.05)$ the rate of blastocyst formation. No improvement in the cell numbers of blastocysts was found when higher concentrations of GTPs $(20$ and $25 \mu \mathrm{M})$ were added to fertilization medium compared to control.

In the third experiment (Table 3), oocytes were matured in vitro and fertilized in GTPs-free medium. Subsequently, the zygotes were cultured in IVC medium supplemented with GTPs at various concentrations. There was no significant difference in cleavage rate between the treatment and control groups $(\mathrm{P}>0.05)$. The addition of $15 \mu \mathrm{M}$ GTPs during IVC increased the rate of blastocyst formation and blastocyst cell number compared to control. However, the blastocyst rate and the cell numbers in blastocysts were significantly reduced $(\mathrm{P}<0.05)$ when $25 \mu \mathrm{M}$ GTPs was added to the medium compared with $15 \mu \mathrm{M}$ GTPs supplementation.

\section{Discussion}

The present study assessed the effects of GTPs supplementation during IVM, IVF and IVC on the developmental competence of bovine oocytes. The principal finding is that supplementation with $15 \mu \mathrm{M}$ GTPs during IVM and IVC improves the rate of blasto- 
cyst formation. However, the blastocyst rates were not improved by supplementation with 20 or $25 \mu \mathrm{M}$ GTPs during IVM and IVC. Also, supplementation with GTPs at different concentrations $(0,10,15,20$, or $25 \mu \mathrm{M})$ during IVF did not improve the proportion of embryos reaching the blastocyst stage.

To our knowledge, the present study is the first to demonstrate the beneficial effect of GTPs supplementation of IVM or IVC medium on early bovine embryo development. Tea polyphenols, especially GTPs, have been shown to be useful as antidiabetic, antitumor, antiarthritic, and antioxidant agents (18-21). The antioxidant effects of tea polyphenols are thought to be associated with their ability to stimulate the antioxidant defense metabolism through redoxregulated transcription factors and mitogenactivated protein kinase-dependent cell cycle regulation $(22,23)$.

The present results indicate that the addition of $15 \mu \mathrm{M}$ GTPs to the defined IVM medium (Experiment 1) significantly improved $(\mathrm{P}<0.05)$ the rate of blastocyst formation. This enhancement could be attributed to the efficient GTPs-induced protection of oocytes against oxidative stress during IVM. It has been reported that other antioxidants such as $\beta$-mercaptoethanol, cysteine and cystine added during IVM of bovine oocytes also improve the rate of embryo development to the blastocyst stage (24). These results suggest that supplementation with appropriate GTPs concentrations during IVM could lead to subsequent improvement of embryo development.

The results of Experiment 2 demonstrated that supplementation with low GTPs concentrations $(10 \mu \mathrm{M})$ during IVF had no effect on the percentage of embryos produced, but higher concentrations of GTPs $(15,20$, or $25 \mu \mathrm{M}$ ) significantly reduced the cleavage and blastocyst rates $(\mathrm{P}<0.05)$. Ali et al. (24) and Luvoni et al. (7) reported that antioxidants such as superoxide dismutase and cysteine present during IVF could significantly reduce the percentage of embryos produced, suggesting that ROS might play a positive role during IVF. Furthermore, previous studies implied that ROS were involved in the control of capacitation (25), acrosomal reaction (26) and fertilization (22).

The results obtained here in Experiment 3 indicate that the proportion of oocytes developing to the blastocyst stage was significantly higher $(\mathrm{P}<0.05)$ in the presence of a low GTPs concentration in a defined culture medium. This improvement in embryo development might be due to the antioxidant effect of GTPs, which scavenge ROS during in vitro embryo culture. Embryos are inevitably exposed to high oxygen in vitro, a fact that results in a higher production of ROS (7) than in vivo because of the necessary manipulations with transient exposure to atmospheric oxygen. ROS seems to be responsible for numerous types of embryo damage. ROS such as superoxide anions are able to diffuse and pass through cell membranes and alter most types of cellular molecules such as lipids, proteins and nucleic acids. The consequences are multiple, and include mitochondrial alterations, embryo cell-block, ATP depletion, and apoptosis (27). The detrimental effects of superoxide anion radicals on embryo development have been demonstrated in cattle $(10,28)$. Fujitani et al. (29) reported that the development of bovine embryos to blastocysts was decreased in a dose-dependent manner when free radicals were generated in vitro by the addition of 2,2'-azobis (2-amindinopropane) dihydrochloride to the culture medium.

Interestingly, in our study, supplementation with higher GTPs concentrations (20 or $25 \mu \mathrm{M}$ ) during IVM (Experiment 1) or IVC (Experiment 2) significantly reduced the rates of blastocyst formation. As reported previously (30-32), GTPs have two different actions: an antioxidant action at lower concentrations, and a pro-oxidant action at higher concentrations. These results suggest that GTPs supplementation beyond the optimum 
concentration ranges might have deleterious effects on the in vitro maturation events occurring in both the nucleus and the cytoplasm and on subsequent embryo development.

Our results demonstrate that $15 \mu \mathrm{M}$ GTPs supplementation during IVM or IVC improves the developmental competence of bovine oocytes possibly by protecting the embryos from oxidative stress. However, the GTPs supplementation during IVF may not improve the rate of blastocyst formation.

\section{References}

1. Ho YS, Dey MS, Crapo JD. Antioxidant enzyme expression in rat lungs during hyperoxia. Am J Physiol 1996; 270: L810-L818.

2. Miesel R, Drzejczak PJ, Kurpisz M. Oxidative stress during the interaction of gametes. Biol Reprod 1993; 49: 918-923.

3. Aitken RJ, Buckingham D, Harkiss D. Use of a xanthine oxidase free radical generating system to investigate the cytotoxic effects of reactive oxygen species on human spermatozoa. J Reprod Fertil 1993; 97: 441-450.

4. Nasr-Esfahani MH, Johnson MH. Quantitative analysis of cellular glutathione in early preimplantation mouse embryos developing in vivo and in vitro. Hum Reprod 1992; 7: 1281-1290.

5. Watson AJ, Watson PH, Warnes D, Walker SK, Armstrong DT, Seamark RF. Preimplantation development of in vitro-matured and in vitro-fertilized ovine zygotes: comparison between coculture on oviduct epithelial cell monolayers and culture under low oxygen atmosphere. Biol Reprod 1994; 50: 715-724.

6. Blondin P, Coenen K, Sirard MA. The impact of reactive oxygen species on bovine sperm fertilizing ability and oocyte maturation. $J$ Androl 1997; 18: 454-460.

7. Luvoni GC, Keskintepe L, Brackett BG. Improvement in bovine embryo production in vitro by glutathione-containing culture media. Mol Reprod Dev 1996; 43: 437-443.

8. Umaoka Y, Noda Y, Narimoto K, Mori T. Effects of oxygen toxicity on early development of mouse embryos. Mol Reprod Dev 1992; 31: 28-33.

9. McKiernan SH, Bavister BD. Environmental variables influencing in vitro development of hamster 2-cell embryos to the blastocyst stage. Biol Reprod 1990; 43: 404-413.

10. Nagao Y, Saeki K, Hoshi M, Kainuma H. Effects of oxygen concentration and oviductal epithelial tissue on the development of in vitro matured and fertilized bovine oocytes cultured in protein-free medium. Theriogenology 1994; 41: 681-687.

11. Knapen MF, Zusterzeel PL, Peters WH, Steegers EA. Glutathione and glutathione-related enzymes in reproduction. A review. Eur $J$ Obstet Gynecol Reprod Biol 1999; 82: 171-184.

12. Dufresne CJ, Farnworth ER. A review of latest research findings on the health promotion properties of tea. $J$ Nutr Biochem 2001; 12 : 404-421.

13. Schroeder P, Klotz LO, Sies H. Amphiphilic properties of (-)epicatechin and their significance for protection of cells against peroxynitrite. Biochem Biophys Res Commun 2003; 307: 69-73.

14. Tervit HR, Whittingham DG, Rowson LE. Successful culture in vitro of sheep and cattle ova. J Reprod Fertil 1972; 30: 493-497.

15. Gardner DK, Lane M, Spitzer A, Batt PA. Enhanced rates of cleavage and development for sheep zygotes cultured to the blastocyst stage in vitro in the absence of serum and somatic cells: amino acids, vitamins, and culturing embryos in groups stimulate development. Biol Reprod 1994; 50: 390-400.

16. Bavister BD, Leibfried ML, Lieberman G. Development of preimplantation embryos of the golden hamster in a defined culture medium. Biol Reprod 1983; 28: 235-247.

17. Parrish JJ, Susko-Parrish JL, Leibfried-Rutledge ML, Critser ES, Eyestone WH, First NL. Bovine in vitro fertilization with frozenthawed semen. Theriogenology 1986; 25: 591-600.

18. Ahmad N, Cheng $\mathrm{P}$, Mukhtar $\mathrm{H}$. Cell cycle dysregulation by green tea polyphenol epigallocatechin-3-gallate. Biochem Biophys Res Commun 2000; 275: 328-334.

19. Waltner-Law ME, Wang XL, Law BK, Hall RK, Nawano M, Granner DK. Epigallocatechin gallate, a constituent of green tea, represses hepatic glucose production. J Biol Chem 2002; 277: 34933-34940.

20. Lambert JD, Yang CS. Mechanisms of cancer prevention by tea constituents. J Nutr 2003; 133: 3262S-3267S.

21. Raza H, John A. Green tea polyphenol epigallocatechin-3-gallate differentially modulates oxidative stress in PC12 cell compartments. Toxicol Appl Pharmacol 2005; 207: 212-220.

22. Jiao $\mathrm{HL}, \mathrm{Ye} P$, Zhao BL. Protective effects of green tea polyphenols on human HepG2 cells against oxidative damage of fenofibrate. Free Radic Biol Med 2003; 35: 1121-1128.

23. Williams RJ, Spencer JP, Rice-Evans C. Flavonoids: antioxidants or signalling molecules? Free Radic Biol Med 2004; 36: 838-849.

24. Ali AA, Bilodeau JF, Sirard MA. Antioxidant requirements for bovine oocytes varies during in vitro maturation, fertilization and development. Theriogenology 2003; 59: 939-949.

25. Aitken RJ, Buckingham DW, West K, Brindle J. On the use of paramagnetic beads and ferrofluids to assess and eliminate the leukocytic contribution to oxygen radical generation by human sperm suspensions. Am J Reprod Immunol 1996; 35: 541-551.

26. de Lamirande E, Tsai C, Harakat A, Gagnon C. Involvement of reactive oxygen species in human sperm acrosome reaction induced by A23187, lysophosphatidylcholine, and biological fluid ultrafiltrates. J Androl 1998; 19: 585-594.

27. Guerin P, El Mouatassim S, Menezo Y. Oxidative stress and protection against reactive oxygen species in the pre-implantation embryo and its surroundings. Hum Reprod Update 2001; 7: 175-189.

28. Shamsuddin M, Larsson B, Gustafsson H, Rodriguez-Martinez H. A serum-free, cell-free culture system for development of bovine onecell embryos up to blastocyst stage with improved viability. Theriogenology 1994; 41: 1033-1043.

29. Fujitani Y, Kasai K, Ohtani S, Nishimura K, Yamada M, Utsumi K. Effect of oxygen concentration and free radicals on in vitro development of in vitro-produced bovine embryos. J Anim Sci 1997; 75: 483489. 
30. Yang GY, Liao J, Li C, Chung J, Yurkow EJ, Ho CT, et al. Effect of black and green tea polyphenols on c-jun phosphorylation and $\mathrm{H}(2) \mathrm{O}(2)$ production in transformed and non-transformed human bronchial cell lines: possible mechanisms of cell growth inhibition and apoptosis induction. Carcinogenesis 2000; 21: 2035-2039.

31. Sakagami H, Arakawa H, Maeda M, Satoh K, Kadofuku T, Fukuchi
$\mathrm{K}$, et al. Production of hydrogen peroxide and methionine sulfoxide by epigallocatechin gallate and antioxidants. Anticancer Res 2001; 21: 2633-2641.

32. Chai PC, Long LH, Halliwell B. Contribution of hydrogen peroxide to the cytotoxicity of green tea and red wines. Biochem Biophys Res Commun 2003; 304: 650-654. 